\title{
A!
}

This is an electronic reprint of the original article.

This reprint may differ from the original in pagination and typographic detail.

Knight, John; Fitton, Dan; Phillips, Charlie; Price, Dylan

\section{Design Thinking for Innovation}

\section{Published in:}

The Design Journal

DOI:

$10.1080 / 14606925.2019 .1594950$

Published: 31/05/2019

Document Version

Publisher's PDF, also known as Version of record

Published under the following license:

Unspecified

Please cite the original version:

Knight, J., Fitton, D., Phillips, C., \& Price, D. (2019). Design Thinking for Innovation: Stress Testing Human Factors in Ideation Sessions. The Design Journal, 22(sup 1), 1929-1939.

https://doi.org/10.1080/14606925.2019.1594950

This material is protected by copyright and other intellectual property rights, and duplication or sale of all or part of any of the repository collections is not permitted, except that material may be duplicated by you for your research use or educational purposes in electronic or print form. You must obtain permission for any other use. Electronic or print copies may not be offered, whether for sale or otherwise to anyone who is not an authorised user. 


\title{
The Design Journal
}

An International Journal for All Aspects of Design

ISSN: 1460-6925 (Print) 1756-3062 (Online) Journal homepage: https://www.tandfonline.com/loi/rfdj20

\section{Design Thinking for Innovation. Stress Testing Human Factors in Ideation Sessions}

\author{
John Knight, Dan Fitton, Charlie Phillips \& Dylan Price
}

To cite this article: John Knight, Dan Fitton, Charlie Phillips \& Dylan Price (2019) Design Thinking for Innovation. Stress Testing Human Factors in Ideation Sessions, The Design Journal, 22:sup1, 1929-1939, DOI: $10.1080 / 14606925.2019 .1594950$

To link to this article: https://doi.org/10.1080/14606925.2019.1594950

曲 Published online: 31 May 2019.

Submit your article to this journal $\pi$

山 Article views: 75

View Crossmark data ¿ 


\title{
Design Thinking for Innovation. Stress Testing Human Factors in Ideation Sessions
}

\author{
John Knight ${ }^{{ }^{*}}$, Dan Fitton ${ }^{b}$, Charlie Phillips ${ }^{\mathrm{c}}$ and Dylan Price ${ }^{\mathrm{d}}$ \\ aAalto University of Arts, Architecture and Design \\ bUniversity of Central Lancashire, Child-Computer Interaction Group \\ 'Avanade, London Digital Studio \\ ${ }^{\mathrm{D}}$ Avanade, London Digital Studio \\ *Corresponding author e-mail: john.knight@aalto.fi
}

\begin{abstract}
This paper reports on a series of studies that attempt to unpick the factors that contribute to successful team ideation. Ideation is a popular, structured approach to creative thinking, where the goal is to produce many viable and innovative ideas and concepts. This is often accomplished through structured collaborative workshops that include 'Design Thinking' techniques and methods. The reported studies involved manipulating variables in controlled experiments with subjects (AKA ideators). The sample of ideators, were tasked with generating ideas to solve a challenge and the outcome of their work was measured by quantity and quality of output. The latter criterion was assessed by an expert panel using a standardised evaluation framework. Four variables were employed to understand idea generation success factors. These were identified as common and thus easily applied factors in typical ideation scenarios and included varying levels of participant stimulation (before sessions), presence or absence of a facilitator, application of 'Design Thinking' technique (or not) and lastly, participant profile based on professional background. In this case, participant characteristics were split between designers and non-designers. The different experiments were run, with participants generating ideas in a timeboxed activity in which their outputs were assessed against the various experimental conditions. The findings suggest that counter orthodox thinking, applying the methods (e.g. Round Robin) is less effective than the influence of ideators' differing professional background and their level of stimulation. These conclusions in turn suggest the possibility of extending the effectiveness of workshop facilitation to increase efficiency and quality of output. The paper concludes with pointers on improving ideation. In particular, increasing levels of engagement and immersion among participants and using aspects of game theory are seen as possible areas of further investigation.
\end{abstract}

Keywords: Design Thinking, Ideation, Collaborative Work 


\section{Introduction}

This paper explores the common practice in business and design of idea generation. Ideas are more than intellectual capital and form the basis of plans, proposals and work to realise them into tangible products and services. The study into this area is underpinned by a unique collaboration between industry and academia over one-year period. The authors believe that this kind of cooperation is necessary given the widespread application of 'Design Thinking' methods and the lack of systematic studies of their effectiveness in real-world contexts. Academic contributions came from sciencebased academics from the University of Central Lancashire, as well as design-oriented research from Aalto University. Industry colleagues (Avanade, London Digital Studio ) provided insights into commercial practice and application of Design Thinking, conducted the studies themselves and ensured that outcomes provided actionable improvements to current ways of working.

This paper reports on two studies that explore group ideation. Each one explored the effect of applying techniques to innovation challenges. The studies were exploratory and aimed to optimise how these sessions are run. The results point to an unexpected (and so far, un-reported phenomena) and potentially valuable finding in that 1) experiment subjects' physiological condition (e.g. aroused, relaxed etc) and 2) professional background has a powerful bearing on the number and value of ideas produced by groups. In the studies, better ideas were produced by ideators with higher levels of stimulation, irrelevant of dependent variables, such as whether a facilitator was present in sessions or whether an ideation technique was used or not. A provisional hypothesis was formed early on that commonly used techniques, such as 'analogous thinking', 'crazy $8 \mathrm{~s}$ ' and 'How might we' statements have less effect than conventional wisdom might suggest.

Conversely, more esoteric factors (e.g. subjects physiological state) substantively have a greater effect than the literature suggests. Data from the studies strongly supported the initial hypothesis and so a further experiment was conceived. If participant's physiological condition is a factor in successful idea generation, then perhaps performance (quantity and quality of output) would also vary depending on subject's professional background. In this case, rather than stimulation, Designers' skill in generating new ideas might also have an effect on the ideas produced. Thus, a second experiment was conducted to explore this second research question.

The studies provided a wealth of insights. These include identifying factors that influence idea production performance in general, as well as detailed findings relating to the different ways people perform ideation challenges. Together the studies also provide practical recommendations to improving collaborative activities where numerous and high-quality innovative ideas are required including how engagement might be increased and cohorts most effectively be facilitated. These generalisable insights go beyond the design domain and should help any individual or team produce breakthrough ideas to any problem. Lastly, the results challenge orthodoxy within the design community, that techniques have a proclivity to drive creativity (irrespective of the kinds of people applying them). This perspective is not a new one and was accelerated by the Design Methods movement (Jones, 1970) and is currently manifested in the voguish notion of 'Design Thinking'.

\section{Design Thinking}

Design Thinking has evolved from its academic roots in the 1980s to attain a broad audience in the business community (e.g. Brown, 2008) and beyond. The value of this approach continues to diffuse through the ever-increasing numbers of innovation consultancies, aided by a number of do-it- 
yourself toolkits that have been devised by a number of high-profile design organisations including IDEO. The popularity of Design Thinking, within many fields, has embedded the notion of design as a means to help drive innovation (at the level of new ideas and concepts) in opposition to more tradition marketing led strategies. This potential has been exploited and extended in the era of neoliberalism.

In this, our current epoch, creativity is consumed by entrepreneurial intensive practices. Here, 'business-critical' practices, such as start-up, product (Ries, 2011), lean (Womack et al, 1990) and agile (Beck, et al, 2001), fuse with (neo)liberalist 'Design Thinking'. These varied component influences share a commonality, in constituency (multidisciplinarity) and focus; short term gain through continuous, incremental change and appreciation of fast tangible outcomes (as opposed to strategic/blue sky thinking). These values closely align with neoliberalism and are reified through the activities and outcomes of ideation sessions. Such sessions are therefore, to some extent, the symbolic habitus (Bourdieu, 2005) of entrepreneurial intensive practices and uniquely frames design as a facilitation function.

Design Thinking is underpinned by a foundational 'accounts' (as opposed to empirical based theory) that focus on how creativity works at the level of cognition. While lacking scientific validation, these popular narratives have bolstered Design Thinking through a kind of pseudo-scientific endorsement. The popularity of Design Thinking does, however, relate back to intrinsic and extrinsic value in demonstrably 'productising' problem-solving based on how designers (perhaps) think and do. In envisioning new products and services, Lawson (2009) states that designers are 'futurologists' in speculating about what could be. This resonates with Simon (2001) who suggests that design is about realising how things ought to be and also realising goals. Chapman (2005) meanwhile, argues that design is a utopian endeavour in conceiving something new and better.

Buchanan (2006) argues that design thinking 'solves' 'wicked problems' that defy logical progression from problem to solution. Rittel and Webber (1973) coined this phrase to describe intractable issues where 'the problem is not understood until after the formulation of a solution' (Conkin, 2009). Unpicking these problems and creating good solutions is best done by reframing (via provisional concepts) rather than the procedural logic that typifies the sciences. This strategy can then be operationalised into the various techniques which are integral to design thinking, described earlier.

Lawson cites Schön's (1983) use of such cognitive (re)framing as an activity that helps cope with difficulty and divergence. Rather the dynamic facets of creative problem solving are in a continual iterative or dialogical loop. Unlike the many theories and frameworks in this area, this model has empirical validity. For example, Stempfle and Badke-Schaub (2002) identify three constructs of Design-led problem solving as:

- Analysis - focus on the problem, understanding the requirements, constraints and opportunities;

- Ideation - focus on solution, generating ideas and creativity; and

- Assessment - focus on evaluation, rationalising and comparing and synthesising.

Naturally these three constructs, while semantically separate, all contribute to moving from unstructured problem to viable (and hopefully novel) solution. Analysis involves deep understanding of the context and specifics of the problem/opportunity. Strong foundational knowledge fosters anchoring, but at the same time can inhibit novelty or 'out of the box' thinking. The kind of radical ideas and concepts that emerge from good ideation, so the orthodoxy goes, can transform highly constrained, complex problems into highly innovative solutions, that help organisations leapfrog 
their competitors and enable them to deliver tangible, progressive change. Similarly, rigorous evaluation of solutions provides checks and balances against depth of needs analysis versus novelty of solution. Arguably, both analysis and assessment are more strongly aligned to an analytical mindset, which ideation techniques attempt to tap into through the methods. Much of the literature on how creative minds work is conjecture, however, this work supports the orthodoxy with one critical nuance. Seasoned practitioners were found to ideate better than novices. Rather than this being due to some innate characteristic of creatives (as the orthodoxy might suggest) we believe this is due to task frequency - practice makes perfect.

\section{Ideation}

Ideation is usually done in groups, on the basis that cohort size correlates with quantity and quality of outputs. Idea generation is also most commonly rationalised as replicating creative cognitive processes and structuring activity to optimise the fuzzy challenge of developing ideas. Smallish teams (5 to 10 participants) are usually involved in sessions and facilitation aims to foster a 'designerly' way of thinking and doing in groups. However, similar techniques are found in engineering (e.g. TRIZ, Savransky, 2000) and many practices and methods have emerged outside of academic research.

Popular idea generation techniques include vernacular examples such as 'round robin' and 'crazy 8s' as well as more solidly research-based techniques that often draw on the work of Edward de Bono (1995). de Bono published a number of works that introduced foundational terms such as 'lateral thinking' through best-selling books, such as 'Serious Creativity' (ibid). The various techniques described in these publications, not only have a natural affinity with Design Thinking, but are arguably the tangible foundations of this way of problem solving.

Within the design literature a number of studies have been undertaken to explore the effect of idea generation methods within the tightly defined context of early concept development. These include Laamanen \& Seitamaa-Hakkarainen (2014) whose study investigated professional designers use of the various techniques. Identifying ways to measure effectiveness of the techniques has also been explored (e.g. Shah et al, 2003). Lastly, Faste et al (2013) extend the analysis to explore the effectiveness of the approach in remote collaborative work. Surprisingly, little empirical work beyond these exist, despite the broad interest and uptake of Design Thinking.

Random input was tested in our first study as this ideation method as it is a commonly used variation of de Bono's lateral thinking. This technique has been operationalised in various ways and is found in many toolkits. While the method is named differently in the variety of applications the fundamental process is the same in using stimuli to help produce novel ideas. In its classic 'Lateral' form random input entails using an arbitrary word, picture, or even sound, as a catalyst to stimulate new and lateral ways of thinking a problem or opportunity (e.g. how might we reduce packaging). The predefined stimuli, (e.g. Tiger), helps ideators anchor thinking outside conventional boundaries by forcing convergence on a single and unrelated topic. Participants write down characteristics pertaining to the stimulus (e.g. fierce, endangered, alert, fast etc) in order to think divergently. Ideators, then apply these characteristics to the problem at hand. In this example, alert and fast characteristics could stimulate ideas around alerting consumers to the impact of packaging on wildlife or reduce the gap (fast) between food producers and consumers.

In our collective experience, this approach has been applied to many situations, problems and opportunities, including patenting (Knight, 2014), product and service concepting and organisational 
transformation. The technique has also been 'gamified' (Knight, 2008) whereby small, competitive teams (1-3 players) randomly select one of the six 'Ideation Games' that comprise:

Lateral - applies classic analogous thinking to a problem

Liberate - involves deconstructing a problem or solution

Lottery - explores Eno style oblique strategies $(E n o, 1978)$ to reframe problems

Literal - inverts analogous thinking to focus on obvious solutions

Link - joins potential solutions together to reframe the problem

Ladder - operationalises the 5 Whys to both problems and solutions

\section{Study 1}

The first study in this work was based around a group design activity aiming to generate ideas in response to a challenge. This was conducted in order to assess the effectiveness of the Lateral idea generation method. In addition, it sought to understand the effect of a facilitator on the outputs of a group. The study was undertaken with a group of male and female graduates $(n=30)$. All participants were given a brief relating to a challenge to produce 'ideas to improve the workplace'. The study involved randomly assigning experiment subjects into four groups ( $A, B, D$ \& D). Each group consisted of three to four ideators, who had recently graduated and were under the age of thirty. The cohort were then assigned to either morning or afternoon sessions (giving eight groups in total $-A B C D x$ 2). Ideators in the morning sessions took part in the study before taking a work-related interview. The session structure involved briefing all of the groups together using a written brief, which was also read out to the full cohort. The same facilitator, a User Experience Designer, ran all the sessions.

In the afternoon sessions, ideators had completed their work-related interview and were therefore in a different cognitive and physiological state than the other group. In every other respect, all sessions were structured and run in exactly the same way using pre-prepared instructions, questionnaires and equipment. Observational notes were taken throughout the sessions, with a focus on time taken. Outputs on A3 paper from the ideation challenge and surveys were collected at the end for analysis.

Group D included a facilitator and applied the Lateral method. Groups A and B also applied the method. Each of these two groups, however, used a different random input word as stimuli, and were also not facilitated. The fourth group, $(C)$ had neither a facilitator nor applied the structure idea creation method. Groups A, B and D were given 5 minutes to come up with characteristics relating to their random input word and then 5 minutes to use this as a catalyst for generating ideas relating to the challenge. Group $\mathrm{C}$ were given 10 minutes to ideate without using any method or external support. At the end of the activity the groups presented back their ideas to other groups and were given a survey to complete relating to their experience of taking part.

\subsection{Findings}

The pre-interview group participants produced more ideas than their afternoon (post-interview) peers ( 53 vs. 23 across all 4 groups). In terms of groups across both morning and afternoon, group A and $B$ produced the smallest number of designs (12 and 8 respectively). Group C performed much better in term of design number with 24 being produced. The best performing group in terms of design numbers was group D with 31 ideas. Innovation was measured by a mixed cohort of experts $(n=8)$ ranking all of the ideas together using a novelty vs. impact matrix. Within the context of Boden (1991)'s definition of creativity, novelty within the matrix aligned with Boden's definition (difference from other artefacts) and impact within the matrix aligned with Boden's value (utility/performance/attractiveness judged by experts in relation to other artefacts). Ranking of ideas 
using the matrix showed that the morning sessions produced more creative ideas than the afternoon session. Overall, group $D$ generated more ideas in total and these were more innovative than the other groups. It is interesting to note that the presence of a facilitator increased the number of ideas and reduced the time taken to complete the activity, suggesting the use of a facilitator helps promote rapid idea generation. The outputs from the morning session is shown in Figure 1a and the outputs from the afternoon session are shown in Figure $1 \mathrm{~b}$

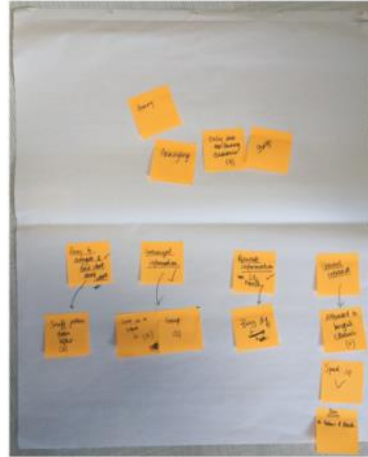

GROUP A

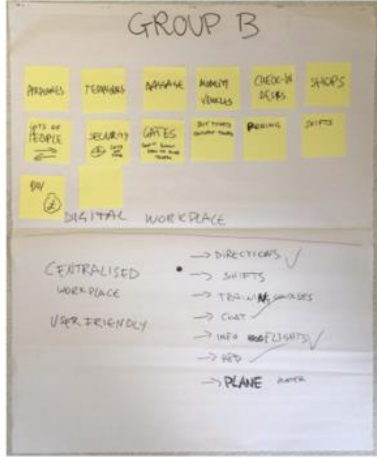

GROUP B

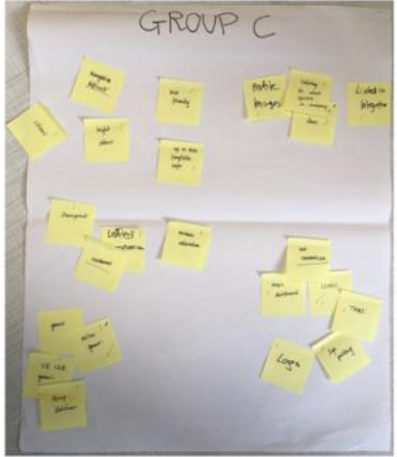

GROUP C

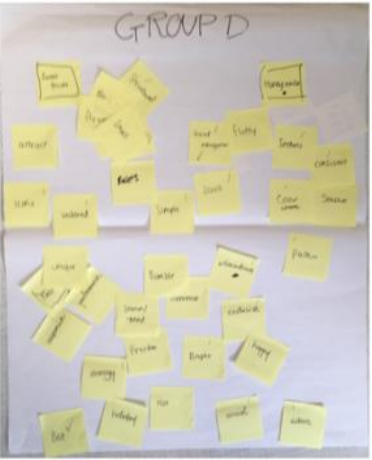

GROUP D

Figure 1a: Outputs from morning session.

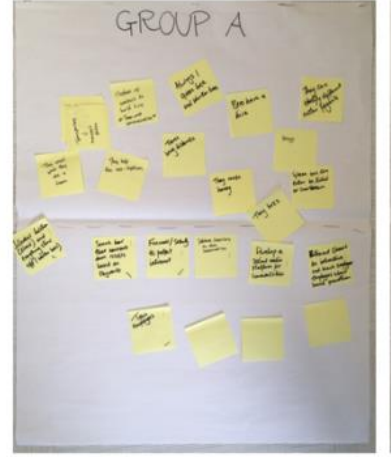

GROUP A

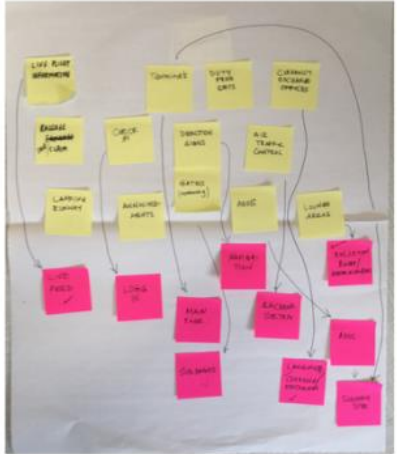

GROUP B

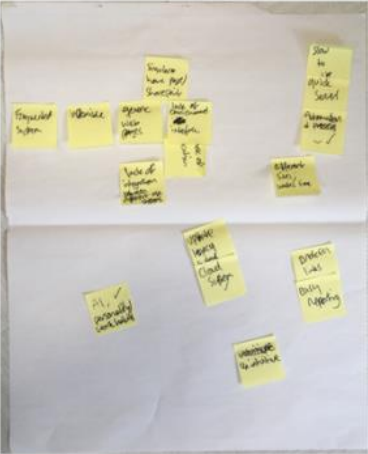

GROUP C

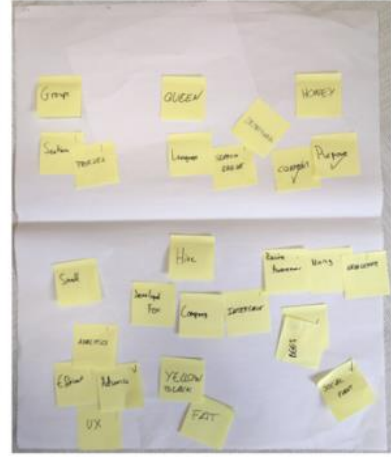

GROUP D

Figure 1b: Outputs from afternoon session.

The groups without a facilitator (but who had applied the method) generated the least number of ideas. This suggests that participant's level of stimulation (pre-interview condition) had more effect on output than either the use of the method or presence of a facilitator. It is hard to draw any conclusion relating to the 'random input' methodology and number or quality of ideas, however survey results prove that those in random input groups ranked the exercise as much more engaging than the control or facilitated group. This suggests random input provides more creative stimulation. 

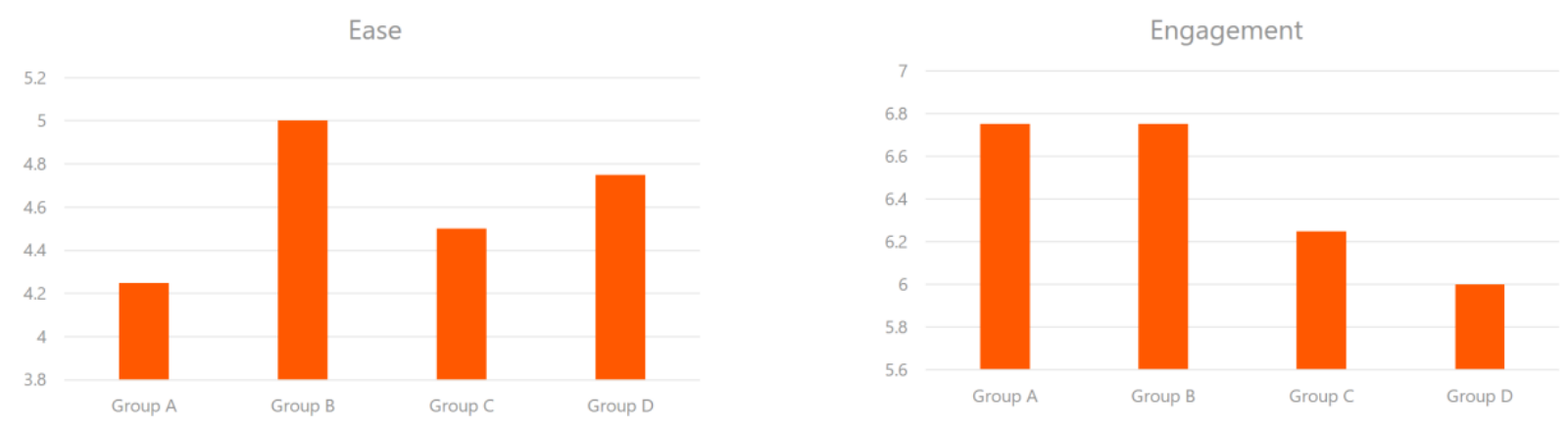

Figure 2: Results from Survey

Figure 2 shows the results from the post-task survey (morning and afternoon responses combined), the variability in responses to the question of 'Ease' is interesting for groups A and B given that the both used the same ideation method. We speculate that the difference in responses is likely related to the different random words used ('Bees' in the case of A and 'Airport' in the case of B) and the challenge in employing these in the design tasks. The random word 'Bees' was also used in group $D$ but the associated Ease score is closer to that of Group B than Group A, the Ease score in Group D (compared to Group A) could be attributed to the facilitator helping to overcome the difficult in applying this unusual random word. In terms of engagement both $A$ and $B$ returned similar high scores while group $D$ returned the lowest, the experiment subjects in groups without facilitators (AC) may have found the lack of supervision afforded more flexibility and fun.

\section{Study 2}

The second study in this work aimed to explore the influence of ideator's professional background on the process within and outputs of a design session. The aim was to run the same design sessions with non-experts and different groups of design experts, observing the entire session to gain insights into methods used and outputs produced. In the study each group was given the context of the food service industry and asked to brainstorm problems for 3 minutes on sticky notes individually, the group as a whole was then given up to 30 minutes to discuss problems and come up with a solution as a group. The same facilitator from Study 1 ran all three sessions in Study 2.

Keeping the design task open ended allowed the groups independence over their choice of methods and outputs. The sessions were video recorded and observational notes were taken throughout, a facilitator was present, but their role was only to give instructions and answer questions as necessary. All groups were provided with A3 paper, flip chart paper, sticky notes and pens. The groups were given consent forms to sign before beginning. The study was carried out with three groups:

- Group 1 consisted of five non-designers working within the same company (job types ranged from IT to finance and HR).

- Group 2 included two service designers (from the same company)

- Group 3 included three UX designers and two visual designers (all from the same company as group one). 


\subsection{Findings}

Each group followed a different process and generated a different type of output. Group 1 (the nondesigners) followed their brainstorming with discussion then began to work together on a solution. The output of the session (Figure 1) was a form of wireframe for a digital kiosk providing an interactive restaurant menu. This group did not apply structured methods nor followed a recognisable process. They also spent the majority of the session time in discussion and struggled to find ways to work in parallel, make decisions as a group, and ensure all groups members were contributing. They were also reluctant to start using the paper for drawing or writing.

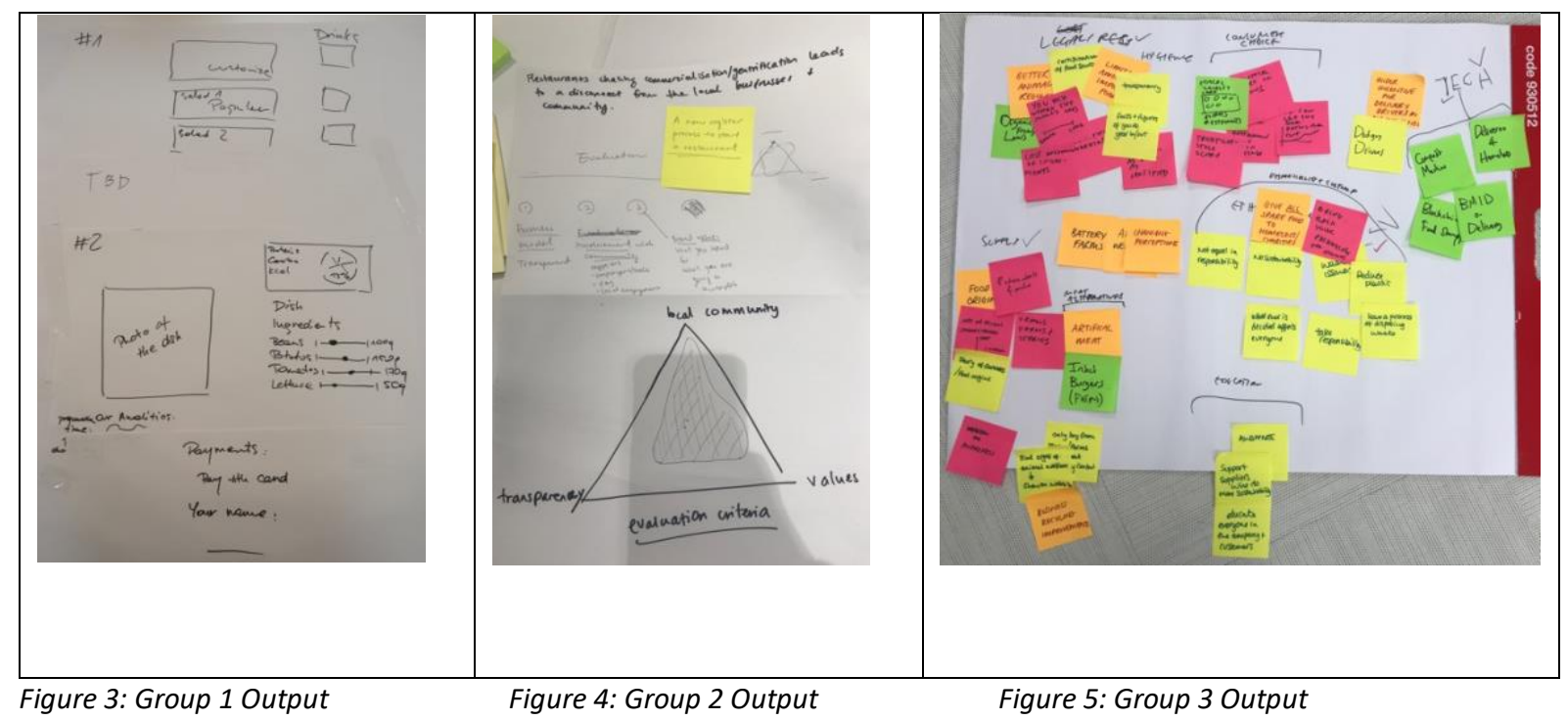

Group 2 (the Service Designers) followed their brainstorming by clustering the identified problems, discussed then chose a cluster, clarified their problem statement and then finally discussed and drew out a solution. The Service Designers appeared to be using techniques frequently applied in their everyday work, like clustering and problem statements. What is interesting to note is that the Service Designers thought about problems at an abstract level and their solution was very business focused (Figure 2).

Group 3 (the UX and visual designers) also followed their brainstorming by firstly clustering the identified problems, next the group voted on which cluster to choose, individual brainstorming of solutions was then done (on sticky notes) in response to the chosen cluster, the solutions were then re-grouped, and finally the group voted on a solution cluster. Their final output (Figure 3) was a collection of relatively technical solution ideas and while the level of abstraction within them was not as high as Group 2's solution, it was at a higher level than Group 1's very concrete kiosk concept. It is interesting to note that this group still had divergence even at the solution phase which contrasted with both of the other groups. It could be suggested that their process is heavily informed by methods frequently used in their discipline, such as clustering, voting, and the 'double diamond' approach to diverging and converging on a problem. The large group size is also likely to have had an influence, while the two members of Group 2 were able to discuss their ideas easily this would have proved more problematic and time consuming with Group 3's five members.

A key comparison between designers and non-designers is that non-designer groups spent much more time discussing as opposed to doing. Designer groups, on the other hand, were more tactile and quicker to use the sticky notes and paper. In addition, designer groups had a level of confidence in following a process that they were familiar with in forming ideas as a group. The familiarity of the designer groups also influenced how they worked, as with musicians who regularly perform together, they often seemed to anticipate other participants ideas and reactions at a non-verbal level. 


\section{Discussion}

Perhaps the most striking findings from Study 1 is the difference in the number of designs ideas created across all 4 groups in the morning and afternoon sessions. The relationship between stress and creativity is known to be complex, with some studies having found that creativity increases in response to stress (Gutnick et al, 2012) and others that stress decreased creativity (Shanteau and Dino, 1993). Other work has shown that the relationship between stress and creativity is influenced by factors such as the type and intensity of the stressor along with the type of stress being induced and personal differences (Byron et al, 2010). From Study 1, it is clear that creativity was suppressed after taking the interview (e.g. stress induced fatigue) and conversely that it was bolstered (e.g. stress induced stimulation) when ideation occurred before the stressor. In conclusion, we believe that physiological stimulation aids creative thinking and this could be enhanced by gentle physical and cognitive activity.

From Study 2 there was a clear distinction between the processes non-designers and designers used and there were different in the output from all three groups. Unsurprisingly the designers instinctively used methods and processes which enabled them to work effectively as a team within the design task. This finding implies the need for support mechanisms such as scaffolding to help enable non-designers to ideate effectively within design activities (e.g. Fitton and Read, 2016). Interestingly all three groups produced different outputs and the types of the outputs had fundamental differences in their level of abstraction, the non-designers (Group 1) being high concrete in their solution and the service designers (Group 3) being the most abstract. The instinctive use of methods / processes by the design professions perhaps points to organizational habits and opens questions such as whether employees from different companies had been selected would other techniques have been used and if so, how would this have influenced the ideation processes.

\section{Conclusion}

While exploratory on nature, these studies provide interesting and controversial data on the efficacy of idea generation methods. Whilst these methods have currency in the design community and broader constituency for Design Thinking, they may not be as effective as heightened levels of participant stimulation or frequency idea generating practices. In either case, while more research is needed to validate the findings, the studies suggest some easy to apply refinements to running ideation sessions. Firstly, low-level cognitive and physiological stimulation should ready participants for creative activity. Secondly, including participants who ideate regularly (whether designers or nondesigners), and at minimum mandating a diverse cohort, should also help generate more and 'better' ideas. Lastly, structuring sessions to maximise engagement through techniques such as gamification can enhance the quality of outputs. In conclusion, there is no single method, nor an ideal cohort mix to generate breakthrough ideas, what we have learned is that ideation is more than cognition but a conceptual activity that is highly dependent on social actors and physiological factors.

\section{References}

Beck, K., Grenning, J., Martin, R. C., Beedle, M., Highsmith, J., Mellor, S., van Bennekum, A., Hunt, A., Schwaber, K., Cockburn, A., Jeffries, R., Sutherland, J., Cunningham, W., Kern, J., Thomas, D., Fowler, M., Marick, B.2001. Manifesto for Agile Software Development. http://agilemanifesto. org, accessed on June 27th, 2018. 
Boden, M. A. (1991). The Creative Mind: Myths \& mechanisms. New York, NY, US: Basic Books.

Bourdieu, P. (2005) 'Habitus', in J. Hillier and E. Rooksby (eds) Habitus: A Sense of Place, pp. 43-52. Aldershot: Ashgate

Byron, K., Khazanchi, S., \& Nazarian, D. (2010). The relationship between stressors and creativity: A meta-analysis examining competing theoretical models. Journal of Applied Psychology, 95(1), 201212.

Buchanan, R. 1992. Wicked Problems in Design Thinking. Design Issues, 8(2): Spring, 5-21.

Chapman, J. (2005). Emotionally Durable Design, Objects, Experiences and Empathy. Earthscan Publications Ltd, London, page 139. ISBN 1844071812.

de Bono , E. 1995. Serious Creativity. Using the Power of Lateral Thinking to Create New Ideas. Harper Collins. London. ISBN 0-00-637958-3.

Eno, B. 1978. Oblique Strategies. Opal, London

Faste, H., Rachmel, N., Essary, R., \& Sheehan, E. (2013). Brainstorm, Chainstorm, Cheatstorm, Tweetstorm: New Ideation Strategies for Distributed HCI Design.In: [Eds]Fleiss, J.L., Levin, B.,Proceedings, CHI 2013, 1343-1352. 12.

Fitton, D., \& Read, J. C. (2016). Primed Design Activities: Scaffolding Young Designers During Ideation. In Proceedings of the 9th Nordic Conference on Human-Computer Interaction (NordiCHI '16). ACM, New York, NY, USA, Article 50.

Gutnick, D., Walter, F., Nijstad, B. A., \& De Dreu, C. K. W. (2012). Creative performance under pressure an integrative conceptual framework. Organizational Psychology Review, 2(3), 189-207.

Jones, J C Design Methods Wiley, Chichester, UK (1970) xxi Gregory, S A 'Design and the design method' in Gregory,

Hacker, W., Sachse, P., \& Schroda, F. (1998). Design Thinking: Possible ways to successful solutions in product development. In H. Birkhofer, P. Badke-Schaub, \& E. Frankenberger (Eds.), Designers: The key to successful product development (pp. 205 - 216). London: Springer. Hacker, W., \& S

Knight, J. (2008) Aggregated Communications Filter. UK patent application no: GB0823452.8. Filing date: $24^{\text {th }}$ December 2008.

Knight, J. 2014. Ideation Games.Design Games to Help Teams Innovate. https://www.slideshare.net/WorldofKnight/radical-innovation-33889361[Accessed10th August 2018]

Lawson, B. 2009. How Designers Think: The Design Process Demystified. London: Architectural Press.

Laamanen, T.-K., \& Seitamaa-Hakkarainen, P. (2014). Interview Study of Professional Designers' Ideation Approaches. The Design Journal, 17(2), 194217. https://doi.org/10.2752/175630614X13915240575988

Ries, E. (2011). The lean startup: How today's entrepreneurs use continuous innovation to create radically successful businesses. Crown Business.

Rittel, H., \& Webber, M. (1973). Dilemmas in a General Theory of Planning. Policy Sciences, Vol. 4, Elsevier Scientific Publishing Company Inc, Amsterdam. Pages 155-169.

Schön , D.A 1983. The Reflective Practitioner: How Professionals Think in Action. Ashgate Publishing Ltd. Aldershot, England.

Shah, J. J., Vargas-Hernandez, N., \& Smith, S. M. (n.d.). Metrics for measuring ideation effectiveness. https://doi.org/10.1016/S0142-694X(02)00034-0 [61]

Shanteau, J., \& Dino, G. A. (1993). Environmental stressor effects on creativity and decision making. In O. Svenson \& A. J. Maule (Eds.), Time pressure and stress in human judgment and decision making (pp. 293-308). New York: Springer.

Savransky, S.D. 2000. Engineering of Creativity: Introduction to TRIZ Methodology of Inventive Problem Solving, CRC Press. 
Schwaber, K. (2004). Agile Project Management with Scrum. Microsoft Press.

Womack J.P., Jones D.T., Roos D. 1990. The Machine that Changed the World: The Story of Lean Production. New York: Harper Perennial. 